\title{
SPECTROPHOTOMETRIC FLOW INJECTION METHOD FOR THE DETERMINATION OF BENDIOCARB INSECTICIDE IN WATER SAMPLES USING CHROMOGENIC REAGENT 2,4-DINITROPHENYLHYDRAZINE
}

\author{
MALIK H ALALOOSH ALAMRI*, SADEEM SUBHI ABED AND ABDUL KAREEM JAWAD ALI
}

Department of Chemistry, College of Science University of Baghdad, AL-Jadriyah, Baghdad, Iraq. Email: malek_eagle@yahoo.com

Received: 14 July 2018, Revised and Accepted: 31 August 2018

ABSTRACT

Objective: Bendiocarb (BEN) is an acutely toxic carbamate insecticide which is used in public places and agriculture. The present study describes a new, sensitive, and accurate flow injection analysis method for the determination of BEN in its pesticide formulations and water samples.

Methods: The developed method is based on an alkaline hydrolysis of BENin NaOH, and the resultant product was coupled with 2,4-dinitrophenylhdrazin in the presence of sodium periodate to form red-colored product which measured at $515 \mathrm{~nm}$.

Results: Under the optimum conditions established (sample volume $150 \mu \mathrm{L}$, flow rate $2 \mathrm{~mL} / \mathrm{min}$, with $75 \mathrm{~cm}$ reaction coil length) for spectrophotometric determination of Bendiocarb. Beer's law is obeyed in the range of $1-150 \mu \mathrm{g} / \mathrm{mL}$ with a detection limit of $0.738 \mu \mathrm{g} / \mathrm{mL}$, with average recovery of 100.737 and relative standard deviation $\%$ of $1.331 \%$.

Conclusion: The established method was successfully applied for the determination of BEN in pesticide formulation and real spiked water sample.

Keywords: Bendiocarb, Flow injection, Spectrophotometric, 2,4-dinitrophenylhydrazine.

(C) 2018 The Authors. Published by Innovare Academic Sciences Pvt Ltd. This is an open access article under the CC BY license (http://creativecommons. org/licenses/by/4. 0/) DOI: http://dx.doi.org/10.22159/ajpcr.2018.v11i10.28478

\section{INTRODUCTION}

Pesticides are extensively worldwide used for agriculture and nonagricultural purposes. Pesticides are recalcitrant pollutants that resist the different levels of degradation either chemical, biochemical, or photochemical, because of their chemical characteristics [1]. Bendiocarb (BEN) is chemically known as 2, 2-dimethyl-1,3benzodioxol-4-yl methylcarbamate (Fig. 1). BEN like other carbamates, this insecticide inhibits the enzyme acetylcholinesterase, necessary for normal transmission of nerve impulses [2,3].

In agriculture, it is used for seed treatment and granular formulations for controlling soil pests and foliage, mainly maize and sugar beet [4]. BEN is also used to eliminate domestic and industrial pests, such as mosquitoes, flies, red ants, and spiders among others [5]. The domestic and industrial use of insecticides, including BEN, has been increased in tropical countries because of the dissemination of diseases whose transmission vectors are insects [6,7]. As for toxicity, toxicological studies of BEN and cases of intoxication in humans have occurred [8]. Many methods have been reported for the spectrophotometric determination of phenols $[9,10]$.

Literature survey revealed that BEN can be determined by several methods such as spectrophotometry [11,12], flow injection analysis [13], high-performance liquid chromatography [14], gas chromatography $[15,16]$, and flow spectrofluorimetry [17].

In the present work, it was possible for the determination of BEN in its formulations and water samples using a simple, accurate, and sensitive flow injection method. A two-channel manifold was employed; the solution of 2,4-Dinitrophenyl hydrazine (DNPH) and $\mathrm{NaIO}_{4}$ solution streams was combined at Y-junction and then merged with injection sample of hydrolyzed $\mathrm{BEN}$ in $\mathrm{NaOH}(0.2 \mathrm{M})$ to form red-colored product which measured at $515 \mathrm{~nm}$.

\section{METHODS}

Apparatus

A digital double-beam recording spectrophotometer Shimadzu UV-visible 260 (Shimadzu, Kyoto, Japan) was used for absorbance measurements using $1 \mathrm{~cm}$ glass cell, in addition to, use of $50 \mu \mathrm{L}$ internal volume, and $1 \mathrm{~cm}$ path length for the FIA measurements. A peristaltic pump (Shenchen, Lab M1, China) was used to transport the carrier solution. An injection valve (Knauer, Germany) was employed to provide appropriate injection volumes. Flexible vinyl tubes ( $0.5 \mathrm{~mm}$ i.d.) were used for the peristaltic pump. Moreover, teflon made reaction coil (R.C) with $0.5 \mathrm{~mm}$ (i.d.).

\section{Chemicals}

The materials and reagents used in this work with high purity, doubledistilled water were used in the preparation of all solutions.

\section{$B E N$}

BEN $(500 \mu \mathrm{g} / \mathrm{mL}$ ) pesticide $(99.0 \%$ purity, M wt. $223.23 \mathrm{~g} / \mathrm{mol})$ was obtained from Bayer (Frankfurt, Germany). A standard stock solution $500 \mu \mathrm{g} / \mathrm{mL}$ of BEN was prepared by dissolving $0.05 \mathrm{~g}$ of pesticides in $4 \mathrm{~mL}$ of ethanol and then completed to the mark with distilled water using $100 \mathrm{~mL}$ volumetric flask. More dilute solutions were prepared by suitable dilution of the stock solution by hydrolyzed in alkaline medium $(\mathrm{NaOH}, 0.2 \mathrm{M})$.

\section{DNPH solution (0.01 M)}

It was freshly prepared by dissolving $0.19814 \mathrm{~g}$ of DNPH (BDH, England, M. Wt $198.14 \mathrm{~g} / \mathrm{mol}$ ) in $4 \mathrm{~mL}$ concentrated sulfuric acid and diluted to the mark with distilled water to obtain $0.01 \mathrm{M}$ solution using $100 \mathrm{~mL}$ volumetric flask; more diluted solution was prepared using simple dilution with distilled water.

\section{Sodium periodate solution $(0.1 \mathrm{M})$}

A $0.1 \mathrm{M}$ of sodium periodates (BHD, England, $99 \%$ purity, mol. wt. $213.91 \mathrm{~g} / \mathrm{mol}$ ) was prepared by dissolving $2.1391 \mathrm{~g}$ in $5 \mathrm{~mL}$ distilled water, and then, the volume made up to mark using $100 \mathrm{~mL}$ volumetric more diluted solution was prepared with the same solvent.

Sodium hydroxide (1 M)

It was prepared by dissolving $4 \mathrm{~g}$ of sodium hydroxide (BDH, England, $\mathrm{M}$. Wt $40 \mathrm{~g} / \mathrm{mol}$ ) and diluted to mark with distilled water using $100 \mathrm{~mL}$ 
volumetric flask to obtain $1 \mathrm{M}$ solution; more diluted solution was prepared with same solvent.

\section{Samples Preparation $(500 \mathrm{\mu g} / \mathrm{mL})$}

The preparation pesticide formulation sample (Ficam $80 \% \mathrm{~W} / \mathrm{W}$, Bayer, Germany) was carried out by weighing $0.0645 \mathrm{~g}$ and dissolved in $5 \mathrm{~mL}$ ethanol and then adequately diluted with distilled water to mark using $100 \mathrm{ml}$ volumetric flask.

\section{Water sample}

About one liter of tap and river water samples was randomly collected from the Tigris river (Baghdad, Iraq). The river water was first filtered off to remove any suspended materials, and all samples were kept in the refrigerator until analyzed. Each sample was spiked with different concentrations of BEN standard solution and subjected to the recommended procedure.

\section{FIA procedure}

A two-channel manifold was employed for the FIA spectrophotometric determination of BEN (Fig. 2). The solution of DNPH (0.001) line and $\mathrm{NaIO}_{4}(0.03 \mathrm{M})$ solution streams were combined at Y-junction, then merged with injection sample $(150 \mu \mathrm{L})$ of BEN (100 ppm hydrolyzed in $0.2 \mathrm{M}$ of $\mathrm{NaOH}$ ), and then mixed in the $75 \mathrm{~cm} \mathrm{R.C}$ at total flow rate of $2 \mathrm{~mL} / \mathrm{min}$. The absorbance of the colored product (red color) was measured at $515 \mathrm{~nm}$.

\section{RESULTS AND DISCUSSION}

In the series of preliminary attempts to ensure the formation of the colored product between BEN and DNPH, the scanning spectrum of the coupling product carried out in range of $220-900 \mathrm{~nm}$ which recorded after obtaining the optimum conditions. The scanning carried out using $20 \mu \mathrm{g} / \mathrm{mL}$ of BEN and $1 \times 10^{-3} \mathrm{M} \mathrm{DNPH}$ in the presence of $0.001 \mathrm{M}$ sodium periodate in alkaline medium (using $0.1 \mathrm{M}$ of $\mathrm{NaOH}$ ). The solutions were mixed in $10 \mathrm{~mL}$ volumetric flask, and the red colored product was formed and gave maximum absorption at $515 \mathrm{~nm}$ when measured against reagent blank (Fig. 3). The spectra of other individual reaction constituents such as BEN, blank, and colored product solutions were recorded as shown in Fig. 3. Therefore, $515 \mathrm{~nm}$ will be used throughout this study as the maximum wavelength.

According to the primary investigation, the aromatic hydrazine group present in DNPH is oxidized by $\mathrm{NaIO}_{4}$ and the resultant product $[18,19]$ coupled with BEN in para position of its phenolic group (after hydrolysis of BEN in alkaline medium) to form red-colored product in alkaline medium of sodium hydroxide solution. Scheme 1 shows the proposed mechanism which indicated the existence of 1:1 (DNPH:BEN).

\section{Optimization of chemical and physical conditions}

According to the pervious primary investigation which is adopted as a basis for developing normal flow injection analysis procedure for the determination of BEN. FIA manifold was designed to provide different reaction conditions for magnifying the absorbance signal generated by the reaction of BEN with DNPH in the presence of $\mathrm{NaIO}_{4}$ in alkaline medium of sodium hydroxide. Initial studies were directed toward the optimization of the experimental conditions, to find the most suitable parameters for the determination of BEN. The study was carried out by altering one factor and keeping the others constant. Each sample was injected 3 times, and the average absorbance was presented. The preliminary conditions for the proposed FIA procedures are summarized in Table 1.

It was observed that the alkaline medium is very essential for the reaction between $\mathrm{BEN}$ and $\mathrm{DNPH}$ in the presence of $\mathrm{NaIO}_{4}$, for developing the colored product; therefore, several alkaline media were examined such $\mathrm{NaOH}, \mathrm{KOH}, \mathrm{NH}_{4} \mathrm{OH}$, and $\mathrm{Na}_{2} \mathrm{CO}_{3}$ with using $0.3 \mathrm{M}$ of each base to select the best one that can give more phenolic product of BEN which can affect on the sensitivity of colored product at $\lambda_{\max }$ of

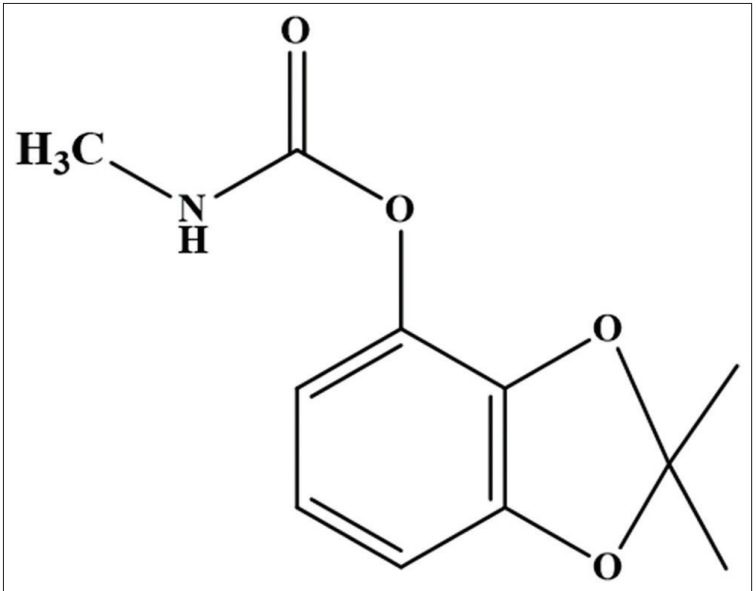

Fig. 1: The chemical structure of bendiocarb $\left(\mathrm{C}_{11} \mathrm{H1}_{3} \mathrm{NO}_{4}\right)$

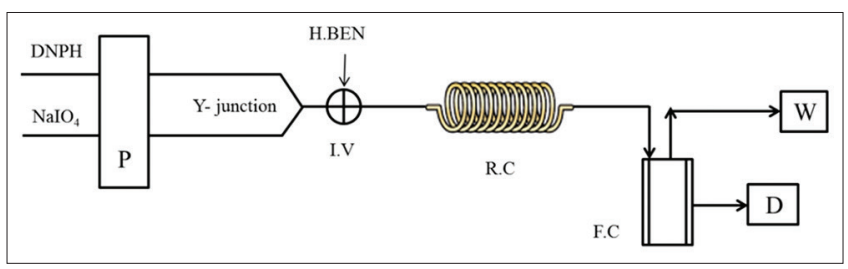

Fig. 2: Schematic diagram of FI manifold, P: Peristaltic pump, I.V: Injection valve, R.C: Reaction coil, F.C: Flow cell, D: Detector, W: Waste, H.BEN: Hydrolyzed bendiocarb in $\mathrm{NaOH}$ solution

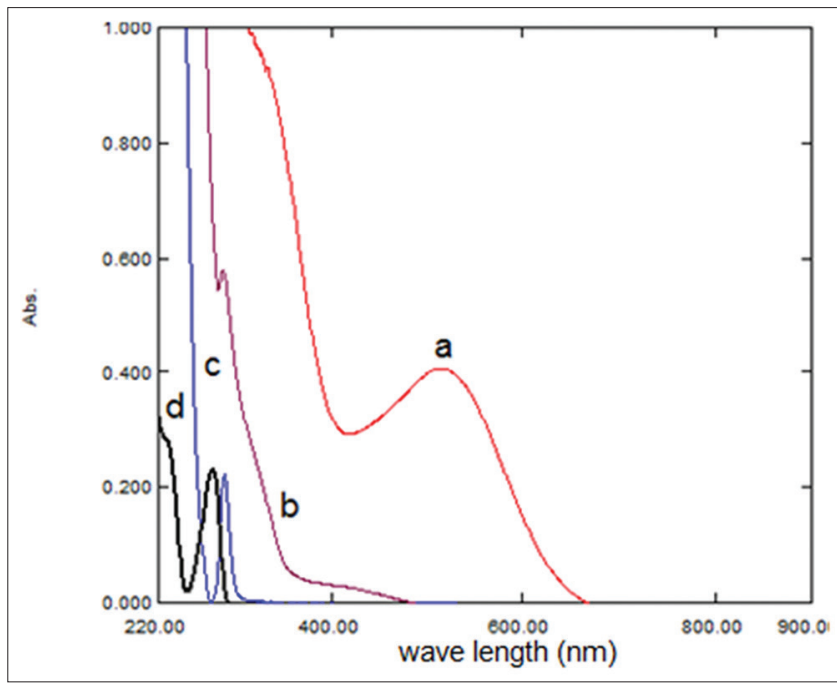

Fig. 3: Absorption spectra of (a) red-colored product (oxidative coupling product), (b) reagent blank, (c) hydrolyzed bendiocarb (BEN) in $\mathrm{NaOH}$, and (d) BEN

Table 1: Preliminary chemical and physical conditions

\begin{tabular}{ll}
\hline Parameter & Value \\
\hline BEN $(\mu \mathrm{g} / \mathrm{mL})$ & $100 \mathrm{ppm}$ \\
Base type & $\mathrm{NaOH}$ \\
Base concentration $(\mathrm{M})$ & $0.3 \mathrm{M}$ \\
DNPH concentration $(\mathrm{M})$ & $0.001 \mathrm{M}$ \\
Oxidation agent & $\mathrm{NaIO4}$ \\
Oxidation agent concentration $(\mathrm{M})$ & 0.05 \\
Flow rate $(\mathrm{mL} / \mathrm{min})$ & 2.4 \\
Sample volume $(\mathrm{mL})$ & 150 \\
Reaction coil $(\mathrm{cm})$ & 50 \\
\hline
\end{tabular}

DNPH: 2,4-Dinitrophenyl hydrazine 


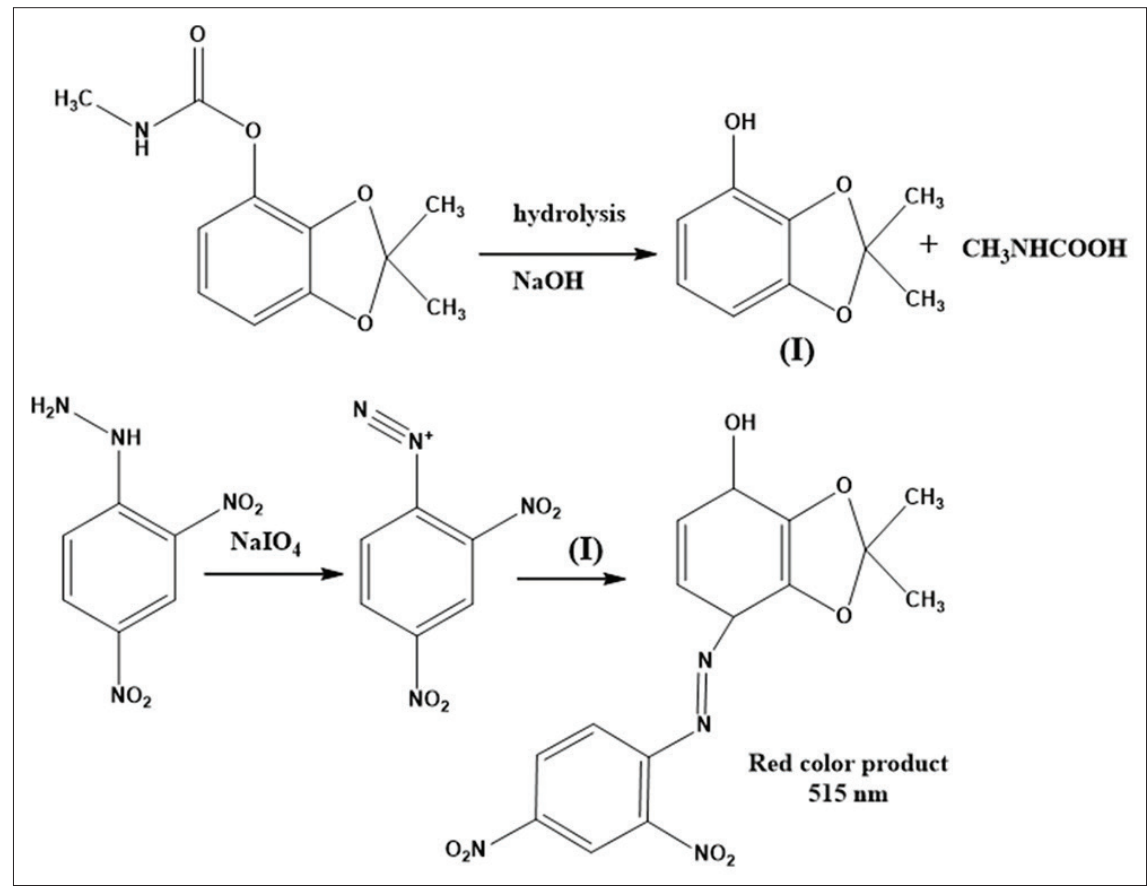

Scheme 1: The proposed reaction mechanism between bendiocarb and DNPH in the presence of $\mathrm{NaIO}_{4}$ and sodium hydroxide solution

$515 \mathrm{~nm}$. Fig. 4 shows that $\mathrm{NaOH}$ gave the best absorbance compared with other alkaline media; therefore, it was chosen for further use in all subsequent experiments.

The effect of different $\mathrm{NaOH}$ concentrations $(0.05-0.4 \mathrm{M})$ was investigated. The results obtained indicated that the absorbance was increased with increasing concentration of $\mathrm{NaOH}$ up to $0.2 \mathrm{M}$, which was selected as optimum concentration in next studies to give the maximum absorbance at $515 \mathrm{~nm}$ as shown in Fig. 5 .

To select the most suitable oxidizing agent used in this study, different types of oxidizing agent $\left(\mathrm{NaOI}_{4}, \mathrm{KIO}_{3}, \mathrm{Ce}^{+4}, \mathrm{~K}_{2} \mathrm{~S}_{2} \mathrm{O}_{7}\right.$, and $\left.\mathrm{K}_{3}\left[\mathrm{Fe}(\mathrm{CN})_{6}\right]\right)$ were investigated using $0.05 \mathrm{M}$ of each one. It was found that $\mathrm{NaOI}_{4}$ gave the maximum absorbance more than other oxidizing agent (Fig. 6) and was used in all subsequent experiments.

The influence of sodium periodate as an oxidizing agent plays an important role in the stage of coupling reaction between the hydrolyzed BEN and DNPH. Therefore, the effect of various concentration of sodium periodate was investigated in a range of $0.005-0.07 \mathrm{M}$. The obtained results (Fig. 7) indicate that the absorbance was increased with the increase in concentration of $\mathrm{NaOI}_{4}$ up to $0.03 \mathrm{M}$. However, the absorbance at any concentration beyond this level $(0.03 \mathrm{M})$ led to decrease in absorbance value. Therefore, the $0.03 \mathrm{M}$ of $\mathrm{NaOI}_{4}$ was selected as the optimum concentration which will be used in the next studies.

The effect of different concentrations of DNPH on the absorption signals was studied according to the recommended procedure through varying the concentration in the range of $0.0001-0.01 \mathrm{M}$. The results of the DNPH concentration are shown in Fig. 8 which indicated that $0.001 \mathrm{M}$ was selected as the optimum concentration due to the negligible blank signal and gave the maximum absorbance. At greater concentrations, the blank signal increased considerably.

The effect of total flow rate on the absorption signal of the colored product was also examined in the range of $0.4-3.6 \mathrm{~mL} / \mathrm{min}$. When the flow rate increased, the signal increased up to a flow rate of $2 \mathrm{~mL} / \mathrm{min}$ (Fig. 9), and there was a decrease for greater flow rates (more than $2 \mathrm{~mL} / \mathrm{min}$ ) because residence time is not enough for the reaction to be completed. A flow rate of $2 \mathrm{~mL} / \mathrm{min}$ was chosen as a compromise

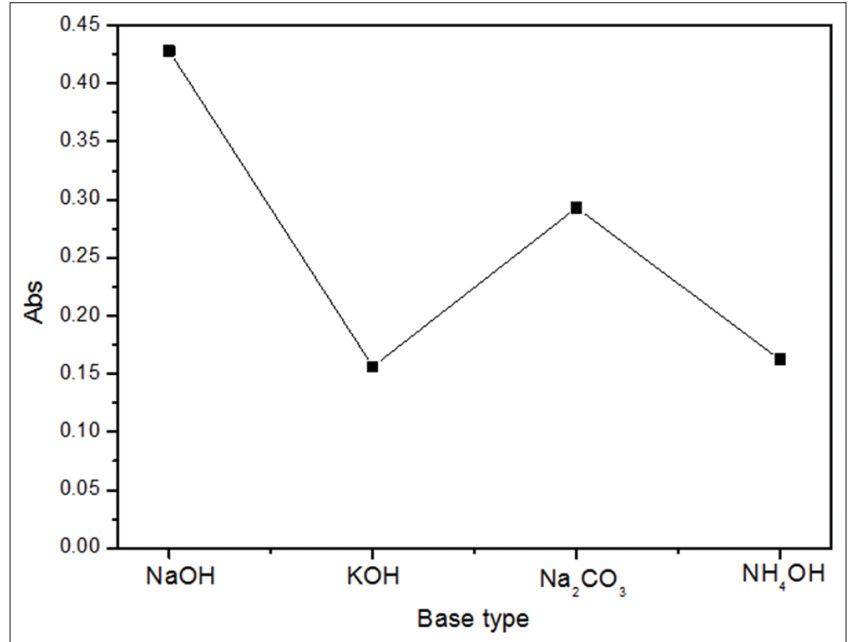

Fig. 4: The effect of base type using $0.3 \mathrm{M}$ of each used base

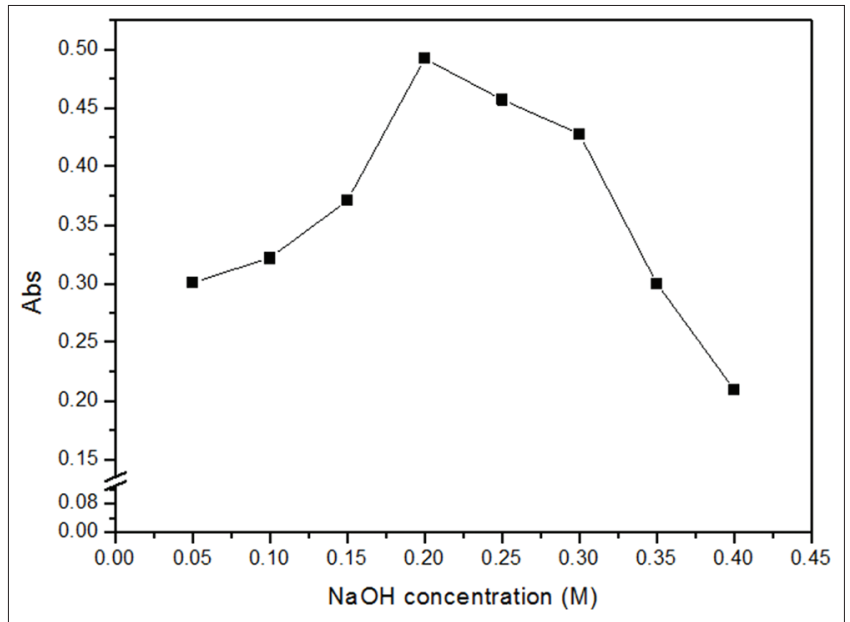

Fig. 5: The effect of $\mathrm{NaOH}$ concentration (M) 
among adequate sampling rate and sensitivity. With this flow rate, a sampling rate of $40 / \mathrm{h}$ was achieved.

The injection volume was investigated with loops in the $75-250 \mu \mathrm{L}$ range. The signal increases with increasing sample volume up to $150 \mu \mathrm{L}$ (Fig. 10a) and remains nearly constant for larger volume.

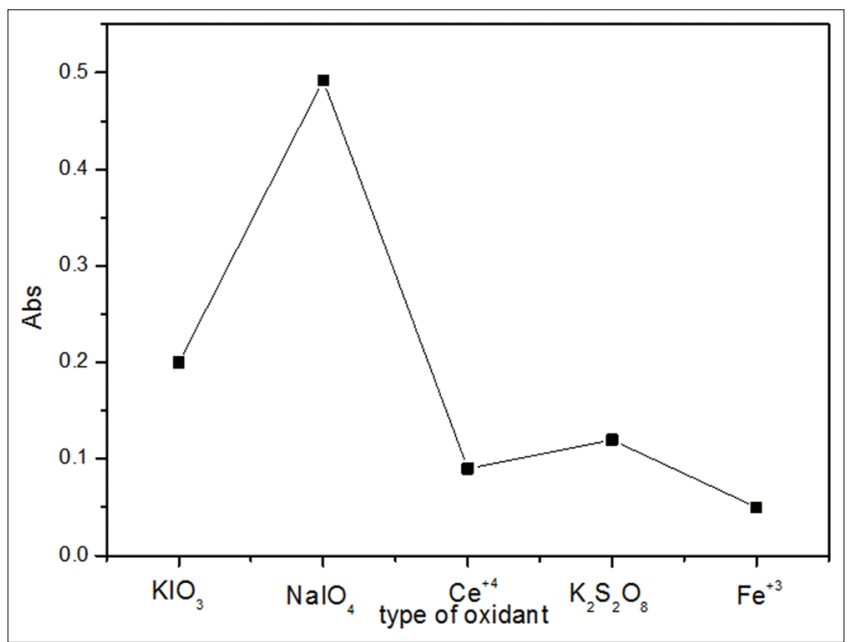

Fig. 6: The oxidizind agent type using $0.05 \mathrm{M}$

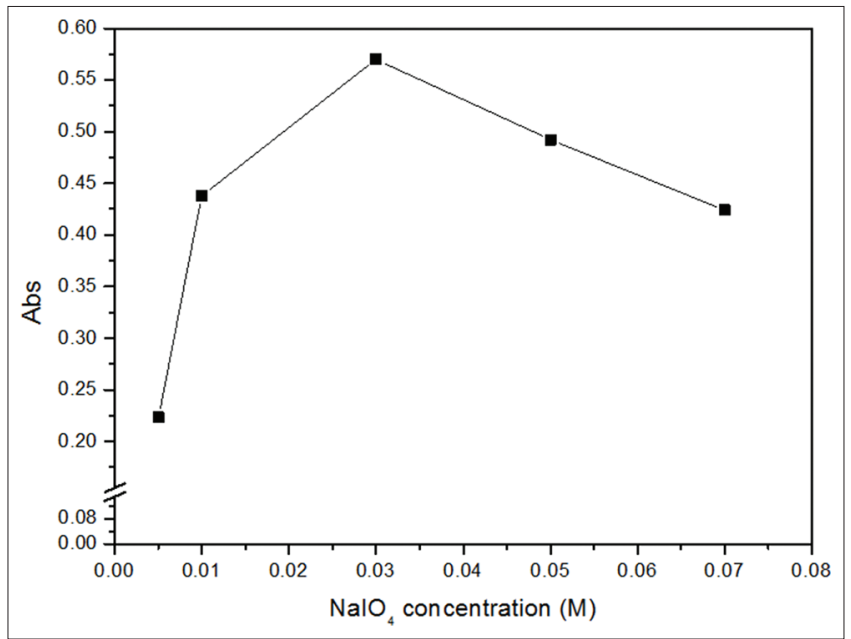

Fig. 7: The effect of periodate concentration effect $(M)$

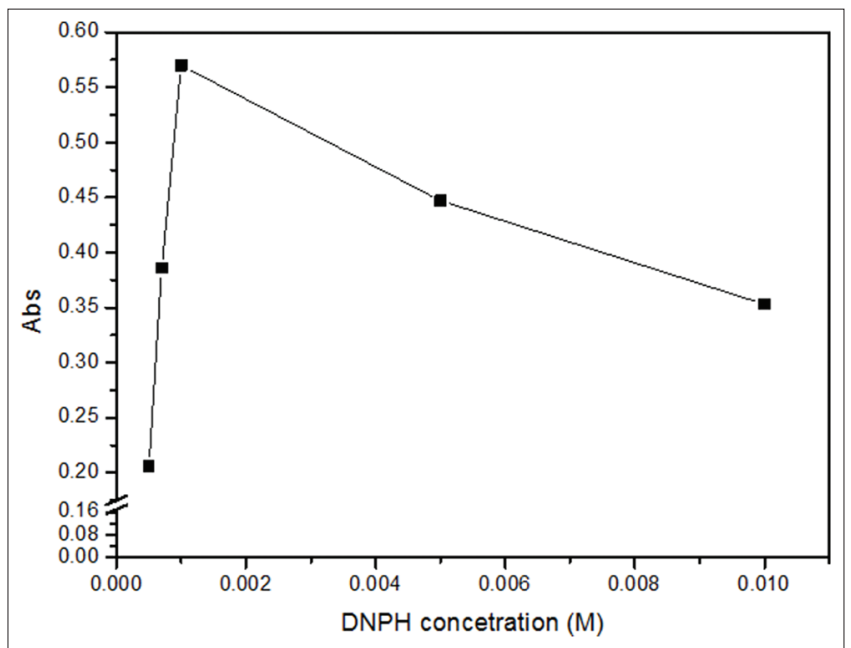

Fig. 8: The effect of 2,4-Dinitrophenyl hydrazine concentration (M)
Above this volume $(150 \mu \mathrm{L})$, a broadening response effect was produced without any increase in the response height. Therefore, a loop of $150 \mu \mathrm{L}$ was selected next studies to maintain a good sampling rate.

The influence of reaction coil length on the sensitivity was studied in a range of 0 (without reaction coil) to $200 \mathrm{~cm}$. The results showed that increase in the length of reaction coil up to $75 \mathrm{~cm}$ leads to increase the sensitivity which is related to the enough residence time for the reaction mixture, whereas a longer reaction coil (more than $75 \mathrm{~cm}$ ) leads to

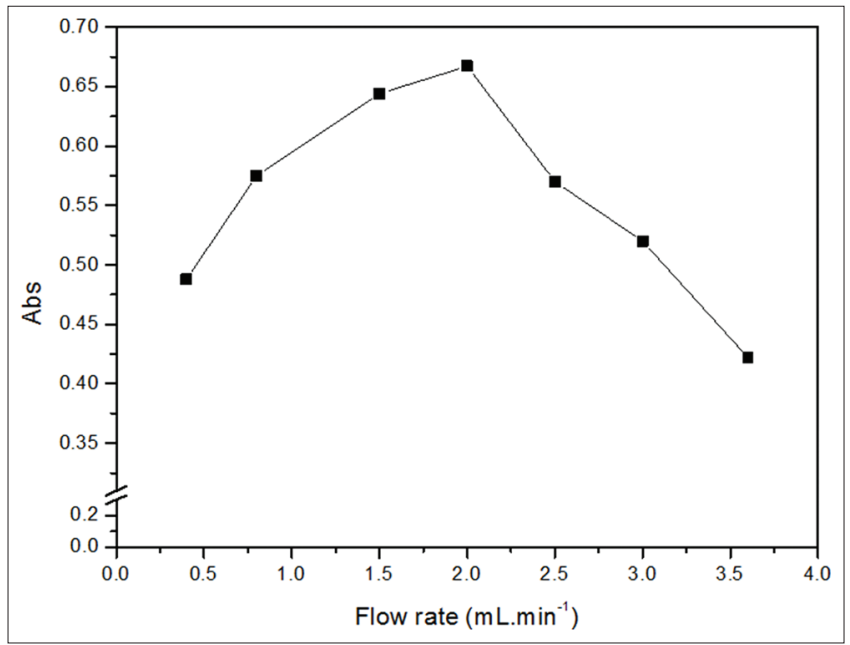

Fig. 9: The effect of total flow rate

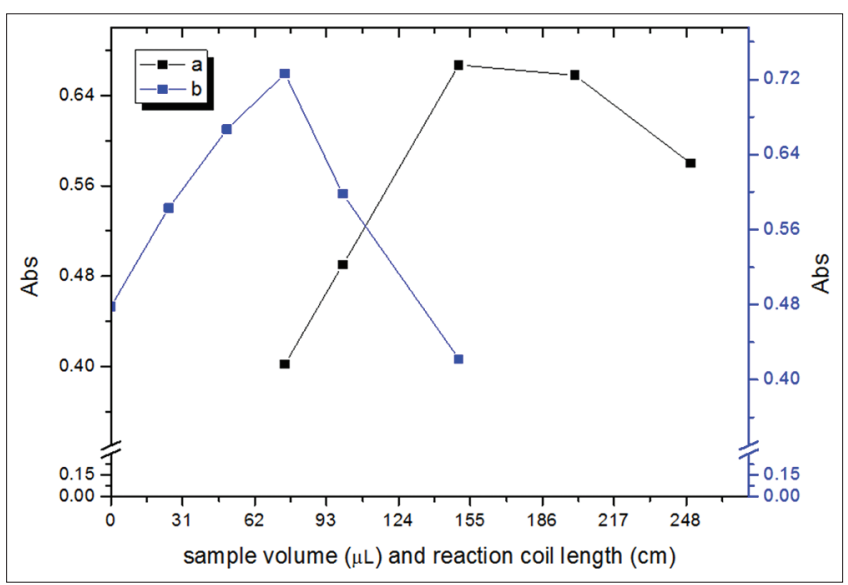

Fig. 10: The effect of (a) Injected sample volume $(\mu L)$ and b) reaction coil length $(\mathrm{cm})$

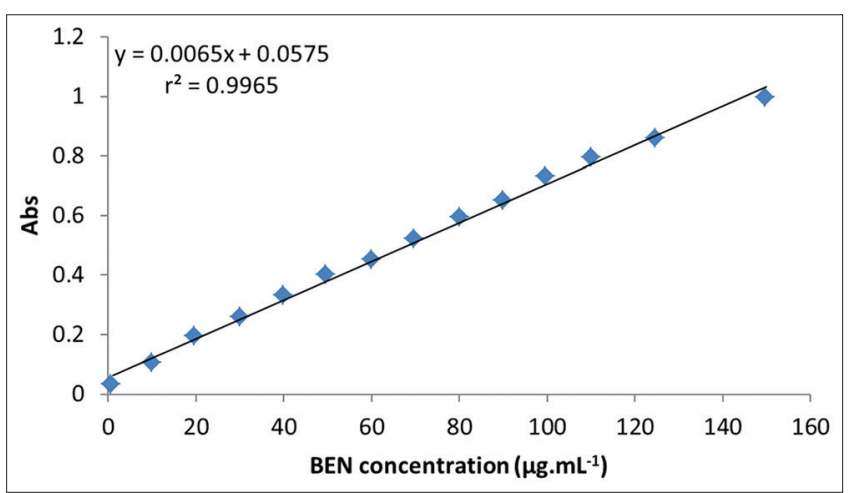

Fig. 11: The calibration graph of bendiocarb under optimum conditions 
decrease sensitivity and also causes response broadening probably due to the dispersion of the sample into the reaction coil. Thus, a $75 \mathrm{~cm}$ (Fig. 10b) was selected as the optimum reaction coil length, which will be used in all subsequent experiments.

\section{Calibration curve}

Under all optimum conditions mentioned in the previous studies. A linear calibration graph (Fig. 11) was constructed in range of 1-150 $\mu \mathrm{g} /$ $\mathrm{mL}$ of BEN standard solution (hydrolyzed with $0.2 \mathrm{M}$ of $\mathrm{NaOH}$ ). Each measurement was repeated 3 times successively. Analytical values of statistical treatments for the calibration graph are summarized in Table $2[20]$.

However, the limit of detection of the proposed method was also calculated [Table 2]. The obtained results have encouraged the proposed method in the estimation of BEN in real samples such as environmental samples to test its applicability and reliability. The developed method in the present work may achieve the requirements of the international standards in terms of the maximum residue limits of BEN insecticide in different types, set by the FAO/WHO [21].

\section{Accuracy and precision [22]}

Under the optimum conditions, the accuracy and precision of the proposed method for the determination of BEN were studied using different concentrations of BEN standard solution $(500 \mu \mathrm{g} / \mathrm{mL})$ or pesticide formulation (ficam). Table 3 shows the value percentage

Table 2: Analytical values of statistical treatments for the determination of BEN calibration graph

\begin{tabular}{ll}
\hline Parameter & Value \\
\hline Regression equation & $\mathrm{y}=0.0065 \mathrm{x}+0.0575$ \\
Correlation coefficient, $\mathrm{r}$ & 0.9965 \\
Linearity percentage, $\mathrm{r}^{2} \%$ & 99.30 \\
Linear range $(\mu \mathrm{g} / \mathrm{mL})$ & $1-150$ \\
Standard deviation of the residuals, $\mathrm{S}_{\mathrm{y} / \mathrm{x}}$ & 0.0180 \\
Standard deviation of the slope, $\mathrm{S}_{\mathrm{b}}$ & $1 \times 10^{-4}$ \\
Standard deviation of the intercept, $\mathrm{S}_{\mathrm{a}}$ & 0.0088 \\
$\mathrm{LOD}(\mu \mathrm{g} / \mathrm{mL})$ & 0.738 \\
$\mathrm{LOQ}(\mu \mathrm{g} / \mathrm{mL})$ & 2.46 \\
\hline
\end{tabular}

LOD: Limit of detection, LOQ: Limit of quantitation, BEN: Bendiocarb of the relative error $\%$, relative recovery $\%$, and percentage relative standard deviation \%, respectively, of five replicates of each concentration, which give a good accuracy and precision value for the proposed method.

\section{Application}

The proposed method was applied (using standard addition method) for the determination of BEN in pesticide formulations (Ficam $80 \% \mathrm{w} / \mathrm{w}$, Bayer, Germany) and spiked water samples. According to the preliminary tests, it was found that all the spiked samples of this study do not have any residue of BEN pesticide. Some water samples including river and tap water - were collected in the city of Baghdad, Iraq. Spiked samples were prepared by the addition of some BEN or Ficam, to obtain the required concentration $(5,10$, and $25 \mu \mathrm{g} / \mathrm{mL})$. The results are summarized in Table 4. The proposed procedure is useful in the control of the BEN in pesticide products.

By comparing the proposed method findings with the reported methods $[23,24]$ in terms of recovery for the water analysis, the F-test and t-test revealed that (Table 5) there is no significant difference between the two methods at $95 \%$ confidence interval. The present method gave satisfactory results for the online determination of BEN in water samples without extraction process.

\section{CONCLUSIONS}

The obtained results indicated that the proposed method is economical with reasonable precision and accuracy for the determination of BEN in pesticide formulation and water samples at a trace level of BEN $(\mu \mathrm{g} / \mathrm{ml})$ by oxidation coupling reaction with 2,4-dinitrophenylhydrazine in the presence of periodate in alkaline medium. The proposed method is superior to the previously reported spectrophotometric method for the determination of BEN in terms of the simplicity, speed (sample throughput of 40 injection/h), and without requiring a temperature or a pH control. Therefore, the method is practical and valuable for routine analysis for the determination of BEN.

\section{AUTHORS' CONTRIBUTIONS}

Sadeem S Abed and Abdul Kareem J Ali conceived of the presented idea. Malik H. A. Alamri developed the experimental procedure and performed the computation. All the authors discussed the results and contributed to the final manuscript.

Table 3: The accuracy and precision of the proposed method for the determination of BEN

\begin{tabular}{lllll}
\hline BEN concentration $(\boldsymbol{\mu g} / \mathbf{m L})$ & REC $\%$ & RE \% & RSD \% n=5 \\
\cline { 1 - 2 } Present & Found & & 1.06 \\
\hline 20 & 20.31 & 101.55 & 1.55 & 1.74 \\
60 & 60.14 & 100.23 & 0.23 & 1.38 \\
120 & 119.70 & 99.75 & -0.25 & 1.20 \\
Ficam pesticide & 19.52 & 97.6 & -2.4 & 1.43 \\
60 & 59.418 & 99.03 & -0.97 & \\
\hline
\end{tabular}

*Average of five determinations. REC \%: Recovery \%, RE \%: Relative error, RSD \%: Relative standard deviation \%, BEN: Bendiocarb

Table 4: Application of the proposed method for determination of BEN in different samples using standard addition method

\begin{tabular}{|c|c|c|c|c|c|}
\hline \multirow[t]{2}{*}{ Sample } & \multicolumn{2}{|c|}{ Concentration of BEN $(\mu \mathrm{g} / \mathrm{mL})$} & \multirow[t]{2}{*}{ REC\% (mean \pm RSD\%) } & \multirow[t]{2}{*}{ RE\% } & \multirow{2}{*}{$\begin{array}{l}\text { Classical method } \\
{[23,24](\text { REC } \% \pm S D)}\end{array}$} \\
\hline & Present & Found* & & & \\
\hline Tap water & 5 & 4.96 & $99.20 \pm 1.09$ & -0.8 & $97.28 \pm 1.45$ \\
\hline & $\begin{array}{l}10 \\
25\end{array}$ & $\begin{array}{l}9.58 \\
24.445\end{array}$ & $\begin{array}{l}95.80 \pm 1.57 \\
97.78 \pm 1.41\end{array}$ & $\begin{array}{l}-4.2 \\
-2.22\end{array}$ & \\
\hline River water & $\begin{array}{l}5 \\
10 \\
25\end{array}$ & $\begin{array}{l}4.88 \\
9.66 \\
24.407\end{array}$ & $\begin{array}{l}97.6 \pm 1.17 \\
96.6 \pm 1.22 \\
97.628 \pm 1.61\end{array}$ & $\begin{array}{l}-2.4 \\
-3.4 \\
-2.372\end{array}$ & $96.42 \pm 1.56$ \\
\hline
\end{tabular}

*Average of five determinations. REC \%: Recovery \%, RE \%: Relative error, RSD \%: Relative standard deviation \%, BEN: Bendiocarb 
Table 5: The comparison of the proposed method with classical methods using t-test and F-statistical tests

\begin{tabular}{lll}
\hline Sample & Rec $\%$ & \\
\cline { 2 - 3 } & Proposed method & Classical method \\
\hline Pure BEN & 100.51 & 95.90 \\
Tap water & 97.60 & 97.28 \\
River water & 97.276 & 96.420 \\
t $(2.776)$ & +1.75 & - \\
F $(19.0)$ & 6.53 & - \\
\hline
\end{tabular}

REC \%: Recovery \%, BEN: Bendiocarb

\section{CONFLICTS OF INTEREST}

Authors have no conflicts of interest.

\section{REFERENCES}

1. Christos AD, Ilias GE. Pesticide exposure, safety issues, and risk assessment indicators. Int J Environ Res Public Health 2011;8:1402-19.

2. Wood A. Compendium of Pesticide Common Names. London: Index, Bendiocarb; 2016.

3. Eckert S, Eyer P, Worek F. Reversible inhibition of acetylcholinesterase by carbamates or Huperzine A increases residual activity of the enzyme upon soman challenge. Toxicology 2007;233:180-6.

4. Worthing CR. The Pesticide Manual: A World Compedium. $7^{\text {th }}$ ed. Lavenham, Suffelk: Lavenham Press Ltd.; 1983.

5. Lozano-Fuentes S, Hayden MH, Welsh-Rodriguez C, Ochoa- Martinez C, Tapia-Santos B, Kobylinski KC, et al. The dengue virus mosquito vector Aedes aegypti at high elevation in Mexico. Am J Trop Med Hyg 2012;87:902-9.

6. Cetron M. Revision to CDC'S zika travel notices: Minimal likelihood for mosquito-borne zika virus transmission at elevations above 2,000 meters. Morb Mortal Wkly Rep 2016;65:267-268.

7. Dhimal M, Gautam I, Joshi HD, O'Hara RB, Harens B, Kuch U. Risk factors for the presence of chikungunya and dengue vectors (Aedes aegypti and Aedes albopictus), their altitudinal distribution and climatic determinants of their abundance in central Nepal. PLoS Negl Trop Dis 2015;9:e0003545.

8. Petrovova E, Purzyc H, Mazensky D, Luptakova L, Torma N, Sopoliga I, et al. Morphometric alterations, steatosis, fibrosis and active caspase-3 detection in carbamate bendiocarb treated rabbit liver. Environ Toxicol 2015;30:212-22.

9. Israa MJ, Sadeem SA. Flow injection spectrophotometric determination of naringenin in supplements using solid-phase reactor containing immobilized manganese dioxide. Asian J Pharm Clin Res 2018;11:473-8.

10. Patel PA, Dole MN, Shedpure PS, Sawan SD. spectrophotometric simltaneos estimation of salbutamol and ambroxol in bulk and formulation. Asian J Pharm Clin Res 2011;4:42-5.

11. Saadyah AD, Jehan SH, Kareem DK. Spectrophotometric determination of bendiocarb after synthesis a new colored compound with a para-amino phenol in environment water sample. Int J Chem Sci 2015;13:415-31.

12. Zuhair A, Suher SA. Micelle-mediating extraction combined with visible spectrophotometry for the determination of ultra trace amounts of bendiocarb insecticide in various matrices after oxidative coupling with O-Toluidine. Int Res J Pure Appl Chem 2016;10:1-16.

13. Alvarez-Rodriguez L, Esteve-Romero J, Escrig-Tena I, AlvarezCoque MC. Flow-injection spectrophotometric determination of phenolic drugs and carbamate pesticides by coupling with diazotized 2,4,6-trimethylaniline. J AOAC Int 1999;82:937-47.

14. Menezes M, Fèlix G. On line extraction and separation of bendiocarb, methomyl, methyl parathion, and pentachlorophenol pesticides from raw milk. J Liq Chromatogr Relat Technol 1998;21:2863-71.

15. Szeto S, Wilkinson A, Brown M. A gas chromatographic method for the determination of bendiocarb in soil and corn: Application to the analysis of residues in corn. J Agri Food Chem 1984;32:78-80.

16. Farber H, Scholer F. Gas chromatographic determination of carbamate pesticides after flash-heater methylation with trimethylsulfonium hydroxide. J Agri Food Chem 1993;41:217-20.

17. Pacioni N, Veglia A. Determination of poorly fluorescent carbamate pesticides in water, bendiocarb and promecarb, using cyclodextrin nanocavities and related media. Anal Chim Acta 2007;583:63-71.

18. Al-Abachi MQ, Sadeem S. Flow injection-spectrophotometric determination of salbutamol sulphate and pyridoxine hydrochloride using 2,4-dinitrophenylhydrazine. Iraqi J Sci 2013;54:6-16.

19. Al-Abachi MQ, Sadeem S. Flow injection-spectrophotometric determination of phenylephrine hydrochloride and amoxicillin trihydrate in pharmaceutical preparations. J Al-Nahrain Univ 2013;16:42-52.

20. Miller JN. Statistics and Chemometrics for Analytical Chemistry. $6^{\text {th }}$ ed. United Kingdom: Pearson Education Limited; 2010.

21. Codex Alimentarius Commission. Pesticides Residue in Food. $2^{\text {nd }}$ e: Joint FAO/WHO Food Standard Programme of United Nations;. p. 127.

22. Harris DC. Quantitative Chemical Analysis. $7^{\text {th }}$ ed. California: Michelson Laboratory, China Lake; 2007.

23. Kumar KS, Suvardhan K, Rekha D, Kiran K, Jayaraj B, Janardhanam K, et al. Development of simple and sensitive spectrophotometric method for the determination of bendiocarb in its formulations and environmental samples. Environ Monit Assess 2007;127:67-72.

24. Leo ML, Hamir SR. Handbook of Pesticides: Methods of Pesticide Residues Analysis. New York: Taylor and Francis Group; 2010. 